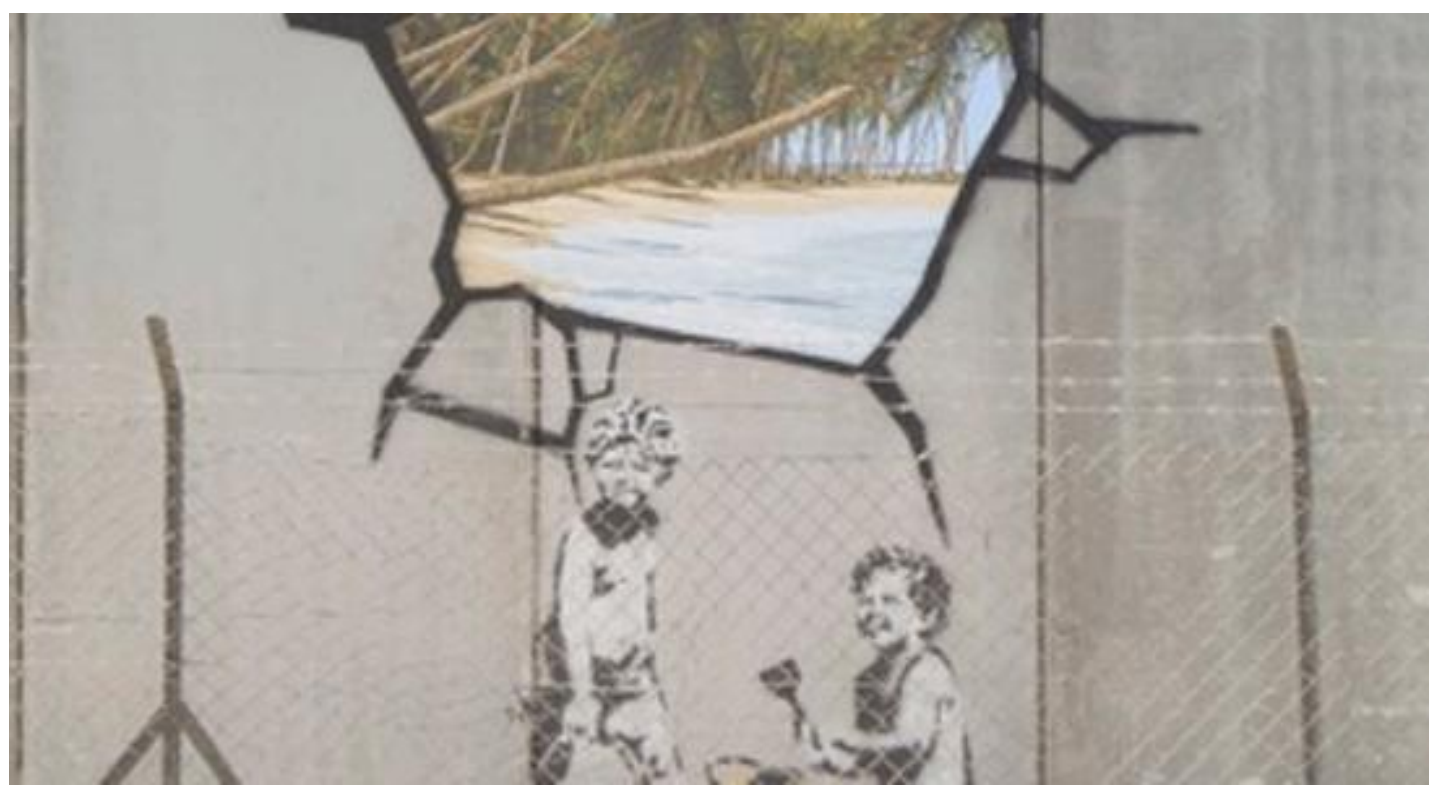

\title{
A ironia exacerbada vira nada. Nada? Incômodos com Narradores de Javé
}

(The extreme irony becomes nothing. Nothing?Troubles with Narradores de Javé)

\author{
Wenceslao Machado de Oliveira $\mathrm{Jr}^{1}$
}

\section{Resumo}

Texto construído como repetição desdobrada, apontando as fragilidades da ironia exacerbada do personagem principal do filme Narradores de Javé. Ironia entrevista como tom enunciador e desmodelizador daquilo que se faz (as estórias, as histórias, as escritas), daquilo que se diz (por aí, por aqui, os outros, nós próprios), daquilo que é (um livro, um filme, uma verdade, uma realidade, uma cidade). Ironia como tom que desconserta, mas também mantém tudo como está: o filme (só) como entretenimento.

Palavras-chave: Narradores de Javé; Ironia; Cinema.

\section{Abstract}

Text built as a split repetition, pointing out the weaknesses of exacerbated irony by the main character from the brazilian movie Narradores de Javé. Irony as a deconstruction and enunciation tone from what it is done (the stories, the histories, the written), from what it is said (there, here, others, ourselves), from what it is (a book, a movie, a truth, a reality, a city). Irony as a tone that disconcert, but also keeps everything as it is: the movie (only) as entertainment.

Key-words: brazilian movie; Narradores de Javé; irony; cinema

\footnotetext{
${ }^{1}$ Professor da Faculdade de Educação, da Universidade Estadual de Campinas (Unicamp). Endereço postal: Avenida Bertrand Russell, 801 - Cidade Universitária Zeferino Vaz - 13083-865 - Campinas-SP. Endereço eletrônico: wences@unicamp.br
} 
Quando é sistemática, a ironia irrita. Nada parece lhe resistir pois nada mais pode ser levado a sério. Essa desenvoltura no que diz respeito à tragédia humana, a exibição da irresponsabilidade, a demissão doentia aparecem como signo de uma destruição de sentido que inflige aos outros as vicissitudes de uma ridicularização sem moderação. A ironia é fácil: nenhum engajamento, nenhuma crença, nenhum ideal, nenhum valor reconhecido, nada além da gozação infernal que destrói o sentido de cada coisa.

Henri-Pierre Jeudy (2001)

Um filme $e^{2}$ que toca num tema político forte para muitos brasileiros: o abandono de suas casas e locais de vivência para que seus territórios sejam inundados pelas águas da represa de mais uma usina hidroelétrica. Narradores de Javé toca na desterritorialização forçada.

Um filme que toca neste tema a partir de outra política: a da escrita como forma de partilha do poder, de potência do poder instituído. Poder este que visa engendrar o futuro ao capturar nas palavras e frases escritas um passado importante, que não pode ser submergido, que não pode ser esquecido.

Um filme que toma a escrita como tema daqueles que não sabem se utilizar dela. O narrador do filme é analfabeto: "não sou um homem das letras", diz ele. A beleza e o mistério do não conhecido. O narrador irá contar a história de sua glória, a história de quando ele tentou salvar o pedaço de chão onde nasceu e viveu das águas que subiriam para levar o progresso para longe dali.

Um narrador que conta lento uma história para preencher o tempo de espera daquele que perdeu o barco, perdeu a travessia e precisa aguardar que o barco volte e lhe leve para o outro lado da represa. Debaixo daquelas águas, Javé persiste em paredes escritas pelo único morador de lá que sabia o desenho das letras. Sabia também que a verdade das palavras é (somente) a verdade das palavras, que a realidade das palavras é

\footnotetext{
2“Nada mudaria a rotina do pequeno vilarejo de Javé se não fosse o fato de cair sobre ele a ameaça repentina de sua extinção: Javé deverá desaparecer inundado pelas águas de uma grande hidrelétrica. Diante da infausta notícia, a comunidade decide ir em defesa de sua existência pondo em prática uma estratégia bastante inusitada e original: escrever um dossiê que documente o que consideram ser os "grandes" e "nobres" acontecimentos da história do povoado e assim justificar a sua preservação. Se até hoje ninguém preocupou-se em escrever a verdadeira história de Javé, tal tarefa deverá agora ser executada pelos próprios habitantes. Como a maioria dos moradores de Javé são bons contadores de histórias, mas mal sabem escrever o próprio nome, é necessário conseguir um escrivão à altura de tal empreendimento. É designado o nome de Antônio Biá, personagem anárquico, de caráter duvidoso, porém o único no povoado que sabe escrever fluentemente. Apesar de polêmico, ele terá a permissão de todos para ouvir e registrar os relatos mais importantes que formarão a trama histórica do vilarejo. Uma tarefa difícil porque nem sempre os habitantes concordam sobre qual, dentre todas as versões, deverá prevalecer na memória do povoado. Na construção deste dossiê, inicia-se um duelo poético entre os contadores que disputam com suas histórias o direito de permanecerem no patrimônio de Javé". Disponível em < $\underline{\text { www.webcine.com.br/filmessi/narrjave.htm }>}$
} 
(sobretudo) a realidade das palavras: "o acontecido tem que ser melhorado no escrito", diz ele.

Um escritor interessado e oportunista que gostava demais da vida que levava em Javé. As palavras lhe serviam para garantir a sua realidade de homem dos correios, aquele que vive em conexão com o que chega e sai do local onde vive. Para manter sua vida tal qual ela era, tornou pública a vida privada, melhorando no escrito o acontecido da vida alheia. E uma vez melhorado o acontecido, ele ficou mais intenso que antes, frutificando-se em mil outros melhoramentos, o que inflamou o povo que destituiu o homem dos correios e o fez proliferar em vida outra, num barraco fora da cidade.

Uma cidade que decidiu, então, viver só nela mesma, sem conexão escrita com o mundo. Fora dali, o acontecido melhorado havia difamado a todos e grassava solto pelos olhos de quem o leu e bocas de quem os continuou melhorando...

Um dia em que a cidade acordou com o sino da igreja a avisar que seu destino era servir ao mundo ao qual tinha renunciado: submergir para que outros locais emergissem com mais força, mais pujança energética: "é preciso sacrificar alguns pela melhoria de muitos", diz um deles, justificando a ação social que a água iria realizar em breve.

Uma cidade que só poderá ser salva se comprovar sua importância para o mundo que ela mesma negou. Mas isto, a escala da importância de Javé, eles - a diretora do filme, os personagens do filme, o narrador do filme - se esqueceram e resolveram contar a nós - os espectadores do filme - a importância daquele lugar para as pessoas do próprio lugar. Tão voltados ao próprio umbigo - diretora, personagens, narrador - não perceberam que enterravam as suas possibilidades antes mesmo de serem submersos em sua ignorância da escritura.

Um escritor exilado foi chamado de volta para salvar a cidade às vésperas do dilúvio invertido - água que sobe - promovido pelos homens e suas necessidades. Escoltado e vigiado, além de orgulhoso de sua importância, o escritor inventivo revelase também um bufão. É chamado para divertir a corte de espectadores que o cinema reúne em sua platéia.

Um irônico exacerbado que

não ri mais verdadeiramente; satisfeito de sua soberania beata, adota a posição convencional de uma negação dos outros e se condena à sua própria perda pelo desprezo que não pára de manifestar. Entrincheirando-se na repetição mecânica dos sarcasmos, exerce sob o mundo um olhar desiludido e cínico que o separa eternamente da comunidade. Acreditando decidir por sua própria ligação com 0 mundo, ele se deixa ser pego pela sua própria armadilha" (JEUDY, 2001, p.74). 
Um bufão que rivaliza com a escrita como marco de poder. Quem escreve é ele, um homem sem credibilidade alguma. Mas quem (o que) deve (se) escrever por meio dele é a ciência. A escrita prescrita como científica regularia a escrita desembestada e alegre de Antonio Biá. "Tudo deve ser científico", diz um personagem. Para tanto, os fatos devem ser rememorados e confirmados pelas histórias contadas pelo povo. Um por um deve contar a sua versão para que os traços do passado sejam ali descobertos, intuídos pela inventividade e esperteza daquele que escuta e registra.

Um bufão que, enquanto os donos do poder em Javé buscam compor a história da fundação do lugar colocando o fundador Indalécio como seu parente distante, ironiza estes narradores e o próprio fundador do lugar, fazendo o povo - personagens e espectadores - rir. Riem eles, personagens, e rimos nós, espectadores, dos donos do poder não poderem garantir a sua verdade, não poderem instituir a sua realidade de glória por descender do fundador. No entanto, o bufão que nos faz rir não ri de si mesmo, nem da escrita que faz, tanto que não escreve o que acha banal. E o que considera importante não escreve em papel, mas nas paredes, matéria mais durável...

Um falador inveterado que impede os silêncios de se manifestarem entre as pessoas e nas pessoas. Não há esquecimentos naquelas pessoas, só há lembranças vívidas e comprovadas por objetos e marcas corporais. Provas científicas dos ditos de cada um, da glória de cada narrador. Não há silêncios, nem sobre o que já se foi e nem sobre o que ainda virá. No entanto, em meio ao falatório continuado, não há nada mais que aqueles traços registrados no livro que permanecerá vazio de palavras.

Um bufão que registra as versões em formas miméticas a elas mesmas: ouvir aquelas histórias é o mesmo que seguir uma formiga pela folha em branco... um traçado aleatório. Ou aquele conjunto de rabiscos, inarticulados como linguagem compreensível pelo raciocínio linguístico, tem potência provocativa de possibilidades poéticas se a mirada para a folha branca cheia de linhas e traçados for de um pintor ou gravurista? As formas dispersas no espaço do quadro-folha seriam grafias de sensações e percepções captadas na fala imaginativa e autoritária de cada um dos que conta a história que quer ter registrada? Mas esta possibilidade poética não se dá no filme, pois neste o registro do traçado aleatório da formiga sobre o papel é apenas a maneira de registrar o desdém de quem escreve por aqueles que não saber ler.

Um desdenhoso inteligente que aproveita aquela dependência dos seus desafetos ao seu domínio de conhecedor da grafia das letras para retornar à vida de amor que tinha com Ritinha e à cachaça que tomava com gosto. Para ele, aquela empreitada era 
completamente absurda, "o quê que este pedaço de chão perdido no mundo tem de importante?", pergunta ele, já afirmando seu veredito e seu "reconhecimento do absurdo [que] legitima a ironia. Se uma ação pode continuar a se cumprir porque tudo é finalmente absurdo, então pouco importa o sentido que lhe é dado e pouco importa se o mundo muda ou não" (JEUDY, 2001, p.74).

Um mundo que muda de maneira desigual. Javé permaneceria talvez a mesma por anos a fio não fosse a represa inundar suas casas e ruas. Ao desaparecer da vista na superfície, a cidade submersa torna-se algo a ser visitado, gestando também, com a mudança para uma Nova Javé, a proliferação daquela vida que, sem a represa, teria tendência a se repetir com mudanças pequenas.

Uma inundação como dádiva que traz a vida como força proliferadora e não como coisa a ser preservada. Vida que se prolifera da própria vida como diferença de si mesma, sendo a mais destacada proliferação de Javé a própria narrativa que é contada no bar e alinhava as demais narrativas do filme. A importância daquela cidade foi ser inundada. Seria esta a ironia maior do filme? Poesia pouco apontada, os narradores seriam todos aqueles que contam a história da ausência da cidade na superfície e do anúncio da cidade submersa.

Uma inundação que gesta a vida proliferada na admiração e deslumbramento de uma mulher e um homem e uma criança que perderam suas casas, mas ganharam outras novas na Nova Javé. Nova Jerusalém onde a energia gerada na usina aponta outros caminhos para uma vida que se desdobra outra de si mesma.

Uma vida proliferada na dor da segunda perda, das perdas acumuladas de não se ter na nova terra nem mesmo aquilo que se tinha na anterior. Onde estão as novas Javés? Em qual círculo infernal lançaram os habitantes das cidades submersas? $\mathrm{Na}$ lamentação constante daqueles que saíram e não tiveram onde chegar? No falatório desenfreado em que terminaram o filme os personagens que, antes de chegar na Nova Javé, já estavam encantados com a possibilidade de contar a história que lhes daria o poder e a glória de ter feito algo memorável a ponto de ser escrito?

Uma "contação" negociada com o único que detém o poder de torná-la história escrita, a ser grafada em suporte que permaneça para além daquele que contou: o papel. Talvez aí esteja uma ironia sutil do filme: não há democracia no hábito de negociar com o poder,

a negociação é ao mesmo tempo o fundamento e a morte da democracia. A demonstração pública da negociação revela quanto à capacidade de absorção das contradições e das oposições é o próprio 
motor do poder. A ironia coletiva advém do reconhecimento implícito e partilhado desse arbitrário constitutivo do poder (JEUDY, 2001, p.57).

Uma ironia que atravessa os corpos dos brasileiros acostumados com uma democracia onde a maioria dos que são ouvidos o são somente para compor o jogo retórico e dissimulado do poder. Se assim considerado, este filme pode ser visto como uma obra da ironia coletiva, aquela sabedoria popular que sabe que "a ironia da comunidade nasce de um reconhecimento da replicação da dissimulação pela superexposição das 'melhores' intenções da gestão pública" (JEUDY, 2001, p.57). Se não há mesmo como sensibilizar o poder para o drama sofrido pelos desterritorializados pelas barragens, então vamos rir juntos.

Um filme que repete o mote do riso fácil para atrair público? Repete o riso fácil e atraiu um certo público. Durante o Narradores de Javé revemos Grande Otelo e Oscarito em seus malabarismos de malandros cinematográficos das chanchadas de anos passados. Revemos também os tantos humoristas da tevê que nos fazem rir daqueles que se levam muito a sério. A tênue distinção que atravessa o filme é entre o riso que movimenta o pensamento, que nos desassossega e o riso que acomoda as coisas onde elas já estavam e de onde nunca pretenderam sair.

Um filme onde a maioria das coisas permanece onde estava, identificadas com um jeito de ser brasileiro.

Contra as incertezas do sentido dado aos eventos atuais, a restauração do passado faz figura de destino. A identidade nunca é perdida pois continua a ser conquistada. Triunfa quando as imagens identitárias se tornam cartões-postais, estereótipos que provocam emoções coletivas, que fortificam o espírito comunitário e passam pelos atributos da sobrevivência de culturas." (JEUDY, 2001, p.62)

Um filme que perdeu sua potência política de exercitar a poesia da linguagem cinematográfica para exercitar a política do cinema como produto de consumo de massa. Fazer rir é garantir público, é repetir o herói macunaímico que atravessa nossa cultura de ir levando vantagem sem ter respeito pelo outro. Mas, ao contrário de Biá, Macunaíma nos fazia rir de nós mesmos: muita preguiça.

Um cinema que perdeu sua potência poética para ampliar sua potência como entretenimento. Mas se mais gente viu, então a potência política do tema ganha relevância? Depende de quem o assistiu. Camadas urbanas acostumadas e desejosas de filmes que atuem politicamente na própria linguagem do cinema devem ter se decepcionado (como eu), uma vez que o filme repete clichês. Comunidades na rota de 
desapropriação de suas terras devido à construção de novas barragens de rios tomam o filme como elemento aglutinador das preocupações comuns. Um filme que tem potência para mobilizar aqueles que irão se deslocar para as águas poderem energizar outras paragens.

Um filme que toma os narradores como divulgadores de algo importante: uma origem. Estaria este filme nos dizendo da importância dos profetas na disseminação de Cristo e seu pai, deus Yaweh? Afinal, é o local e o povo de Javé que se manifestaram e se proliferaram em todos: personagens que esperam o barco ou tomam cerveja, espectadores que esperam o filme terminar para tomar cerveja. Qual a mensagem então? Qual a moral? Ouçam o sino: ele lhes avisará o dia do destino final.

Mas enfim cada um escolhe a negociação que fará no jogo político onde o poético é apenas parte das apostas.

E mais enfim ainda, os incomodados que se mudem... porque "a ironia é o que se partilha melhor" (JEUDY, 2001, p.13).

\section{Referências bibliográficas}

JEUDY, Henri-Pierre. (2001). A ironia da comunicação. Porto Alegre: Sulina.

\section{Filmografia}

Narradores de Javé, Eliane Caffé. Brasil, 2003. 
Para citar essa obra:

OLIVEIRA JR, Wenceslao Machado de. A ironia exacerbada vira nada. Nada? Incômodos com Narradores de Javé. RUA [online]. 2011, no. 17. Volume 1 - ISSN 1413-2109

Consultada no Portal Labeurb - Revista do Laboratório de Estudos Urbanos do Núcleo de Desenvolvimento da Criatividade

http://www.labeurb.unicamp.br/rua/

Laboratório de Estudos Urbanos - LABEURB

Núcleo de Desenvolvimento da Criatividade - NUDECRI

Universidade Estadual de Campinas - UNICAMP

http://www.labeurb.unicamp.br/

Endereço:

Rua Caio Graco Prado, 70

Cidade Universitária "Zeferino Vaz" - Barão Geraldo

13083-892 - Campinas-SP - Brasil

Telefone/Fax: (+55 19) 3521-7900

Contato: http://www.labeurb.unicamp.br/contato 